UTILITY: Jurnal IImiah Pendidikan dan Ekonomi

Volume 4, No. 2, Agustus 2020: Page 36-45

ISSN 2549-1377 (Print) || ISSN 2549-1385 (Online)

Available online at $h$ ttp://journal.stkipnurulhuda.ac.id/index.php/utility

\title{
PERBANDINGAN HASIL BELAJAR IPS PESERTA DIDIK MENGGUNAKAN METODE TANYA JAWAB DENGAN METODE PEER TUTORING DI KELAS VII MTS NURUL HUDA SUKARAJA
}

\author{
Rani martin', Miftakhur Rohmah ${ }^{2}$, Dwi Susanti ${ }^{3}$ \\ ${ }^{1,2,3}$ Program Studi Pendidkan Ekonomi STKIP Nurul Huda \\ *E-mail: martinrani589@gmail.com
}

\begin{abstract}
Abstrak: Masalah dalam penelitian ini adalah bagaimanakah perbandingan hasil belajar IPS peserta didik menggunakan metode tanya jawab dengan metode peer tutoring di kelas VII MTs Nurul Huda Sukaraja. Desain dalam penelitian ini menggunakan Quasi exsperimental design. Pengambilan sampel dalam penelitian ini secara acak melalui pengundian. Teknik pengumpulan data menggunakan tes, dan pengujian hipotesisnya menggunakan uji z. Berdasarkan analisis data penelitian diperoleh nilai rata-rata kelas eksperimen I yang menggunakan metode peer tutoring adalah 80,64 dan nilai rata-rata kelas eksperimen II menggunakan metode tanya jawab adalah 64,20 . Terdapat perbedaan hasil belajar IPS yang signifikan antara peserta didik menggunakan metode tanya jawab dengan peserta didik menggunakan metode peer tutoring di kelas VII MTs Nurul Huda Sukaraja. Hal itu dapat dilihat dari nilai $z_{\text {hit }}=56,7>z_{\text {tabel }}=1,96$. Karena $z_{\text {hit }} 56,7$ tidak terletak diantara $-Z_{1 / 2(1-\alpha)}< \pm Z_{\text {hit }}<Z_{1 / 2(1-\alpha)}$ yaitu $-1,96$ dan $+1,96$ maka Ho di tolak sedangkan $\mathrm{Ha}$ diterima.
\end{abstract}

Kata Kunci: Metode Peer Tutoring, Metode Tanya Jawab, Hasil Belajar

\section{PENDAHULUAN}

Metode pembelajaran adalah cara yang dipergunakan oleh guru untuk menyajikan bahan pelajaran kepada siswa di depan kelas, agar pelajaran tersebut dapat diterima, dipahami dan diterapkan oleh siswa dalam kehidupan sehari-hari. Sutikno (2009:88) menyatakan bahwa metode pembelajaran adalah cara-cara menyajikan materi pelajaran yang dilakukan oleh pendidik agar terjadi proses pembelajaran pada diri siswa dalam upaya untuk mencapai tujuan. Guru hendaknya menguasai berbagai metode pembelajaran agar mampu menyajikan materi pembelajaran dengan baik. Menurut Balqis (2014: 2) Jika guru mampu memilih metode pembelajaran yang tepat atau mampu mengkombinasikan beberapa metode pembelajaran yang menunjang 


\section{PERBANDINGAN HASIL BELAJAR IPS PESERTA DIDIK \\ MENGGUNAKAN METODE TANYA JAWAB DENGAN \\ METODE PEER TUTORING DI KELAS VII \\ MTS NURUL HUDA SUKARAJA}

pemberian materi pembelajaran, maka dalam pembelajaran guru tidak akan monoton dalam menyajikan materi pembelajaran serta tidak akan membosankan bagi siswa pada saat kegiatan pembelajaran berlangsung. Menurut Nasution (2019:10) Penerapan metode pembelajaran merupakan faktor penting yang dapat menentukan hasil belajar yang akan dicapai oleh siswa terutama pada mata pelajaran IPS. Guru dapat memilih dan menentukan metode yang akan digunakan dalam proses pembelajaran berdasarkan bahan pembelajaran, keadaan sarana dan prasarana, dan keadaan siswa (Koswara: 2019).

Berdasarkan fakta di lapangan pada saat pada saat observasi awal pada tanggal 10 September sampai 10 November Tahun 2019 di MTs Nurul Huda Sukaraja masalah pokok yang terjadi masih kurangnya peran aktif siswa dalam proses pembelajaran, sehingga pembelajaran yag terjadi kurang interaktif dan masif. Kegiatan belajar yang masif tersebut berdampak pada hasil belajar siswa yang juga kurang optimal. Hal ini dapat dilihat dari asil ulangan harian IPS di kelas VII MTs Nurul Huda Sukaraja menunjukkan dari 62 siswa, terdapat 32 siswa atau 51,61\% memperoleh nilai di bawah KKM. Rendahnya penguasaan materi pembelajaran IPS diduga karena kurang tepatnya metode pembelajaran yang diterapkan guru. Berdasarkan masalah yang terjadi pada pembelajaran, maka peneliti ingin menggunakan metode pembelajaran yang dapat membuat siswa lebih aktif dan diharapkan dapat memperbaiki hasil belajar IPS siswa. Berdasarkan masalah yang terjadi pada pembelajaran tersebut, maka peneliti ingin menerapkan metode pembelajaran lain yang dapat membuat siswa lebih aktif dan dapat meningkatkan hasil belajar siswa yaitu dengan menggunakan metode tanya jawab dan peer tutoring.

Metode tanya jawab adalah cara penyajian pelajaran dalam bentuk pertanyaan yang harus dijawab, terutama dari guru kepada siswa Djamarah (2010:94). Menurut Asfar dan Nur (2018) Pertanyaan dan jawaban dapat muncul dari guru maupun dari siswa. Masingmasing saling mengisi, baik memberikan pertanyaan maupun jawaban. Lebih lanjut Solatiyah (2016) menyatakan bahwa Inti dari penggunaan metode tanya jawab adalah berusaha menanyakan apakah siswa telah mengetahui fakta tertentu yang sudah dan belum diberikan pada 
proses pembelajaran. Pelaksanaan metode tanya jawab secara tepat dapat mendorong aktivitas siswa, sehingga hasil belajar yang diperoleh siswa akan lebih baik.

Menurut Sani (2013:198-199), metode peer tutoring adalah sebuah metode yang menuntut peserta didik untuk aktif berdiskusi dengan sesama temannya, atau mengerjakan tugas kelompok dengan bimbingan atau arahan teman yang kompeten. Melalui metode pembelajaran peer tutoring, tutor dan anggota diharapkan bekerja sama secara maksimal sesuai dengan kelompoknya. Kerja sama yang dimaksud dalam pembelajaran peer tutoring adalah siswa bertindak sebagai tutor yang berkemampuan tinggi membantu siswa berkemampuan sedang, dan rendah didalam kelompoknya agar dapat memahami materi pembelajaran dan menyelesaikan tugas yang diberikan oleh guru.

\section{METODE}

Jenis penelitian yang digunakan dalam penelitian ini adalah peneletian kuntitatif. Sedangkan metode yang digunakan dalam penelitian ini adalah metode penelitian komparatif. Menurut Sugiyono (2009:57) penelitian komparatif adalah penelitian yang digunakan membandingkan keberadaan suatu variabel atau lebih pada dua atau lebih sampel yang berbeda, atau pada waktu yang berbeda. Analisis komparatif dilakukan dengan cara membandingkan antara teori yang satu dengan yang lain, dan hasil penelitian satu dengan penelitian yang lainnya. Desain penelitian ini menggunakan Quasi exsperimental design (eksperimental semu).

Dalam penelitian ini yang menjadi variabel bebas $(X)$ adalah metode pembelajaran. Metode pembelajaran yang dimaksud dalam penelitian ini adalah metode pembelajaran tanya jawab (X1) dan peer tutoring (X2). Dalam penelitian ini yang menjadi variabel terikat $(\mathrm{Y})$ adalah hasil belajar IPS peserta didik. Populasi dalam penelitian ini adalah seluruh peserta didik kelas VII MTs Nurul Huda Sukaraja yaitu VII-1, VII-2,VII-3, VII-4 yang berjumlah 106 peserta didik. Pengambilan sampel dilakukan dengan mengambil dua kelas sampel dari empat kelas yaitu kelas VII-1 dan VII-4. Satu kelas sebagai kelas eksperimen 


\section{PERBANDINGAN HASIL BELAJAR IPS PESERTA DIDIK \\ MENGGUNAKAN METODE TANYA JAWAB DENGAN \\ METODE PEER TUTORING DI KELAS VII \\ MTS NURUL HUDA SUKARAJA}

I dan satu kelas sebagai kelas eksperimen II .Teknik yang digunakan dalam pengumpulan data penelitian ini adalah menggunakan tes. Teknik analisis data penelitian ini dengan cara menghitung nilai rata rata (average), standar deviasi, dan menentukan tingkat kesukaran soal dengan kategori tinggi, sedang, dan rendah.

\section{HASIL DAN PEMBAHASAN}

\section{Hasil Belajar}

Hasil belajar IPS peserta didik yang menggunakan metode Peer Tutoring ditinjau dari persentase nilai kategori tinggi, sedang dan rendah dapat diketahui bahwa $72 \%$ memperoleh nilai dalam kategori tinggi, memperoleh nilai kategori sedang $24 \%$ sedangkan peserta didik yang memperoleh nilai kategori rendah $4 \%$ dengan nila rata-rata hasl tes sebesar 80,64 . Hasil penelitian menunjukkan bahwa hasil belajar peserta didik kelas VII-1 MTs Nurul Huda Sukaraja adalah tinggi. Data ini menunjukkan bahwa metode Peer Tutoring efektif diterapkan pada mata pelajaran IPS karena metode peer tutoring menuntut peserta didik untuk aktif berdiskusi dengan sesama temannya, atau mengerjakan tugas kelompok dengan bimbingan atau arahan teman yang kompeten.

Hasil belajar IPS peserta didik yang menggunakan metode tanya jawab ditinjau dari persentase nilai kategori tinggi, sedang dan rendah disajikan dalam tabel 4.6 di halaman sebelumnya dapat diketahui bahwa memperoleh nilai dalam kategori tinggi 4,35\%, memperoleh

nilai kategori sedang $21,73 \%$ sedangkan peserta didik yang memperoleh nilai kategori rendah $73,91 \%$ dengan nila rata-rata hasil tes sebesar 64,20 . Hasil penelitian menunjukkan bahwa hasil belajar peserta didik kelas VII-4 MTs Nurul Huda Sukaraja adalah rendah . Data ini menunjukkan bahwa metode tanya jawab kurang efektif diterapkan pada mata pelajaran IPS karena motode tanya jawab ini inti pembelajarannya guru mengajukan pertanyaan-pertanyaan dan siswa menjawab tentang materi yang diperolehnya atau sebaliknya siswa bertanya dan guru menjawab. 


\section{UJI PRASYARAT ANALISIS DATA}

Uji Normalitas Eksperimen I

\begin{tabular}{|c|c|c|c|c|c|c|}
\hline No & Frekuensi & $\boldsymbol{f}_{\boldsymbol{o}}$ & $\boldsymbol{t}_{\boldsymbol{h}}$ & $\left(f_{0}-f_{h}\right)$ & $\left(f_{0}-f_{h}\right)^{2}$ & $\frac{\left(f_{0}-f_{h}\right)^{2}}{f_{h}}$ \\
\hline 1 & $60-66$ & 2 & 1 & 1 & 1 & 1 \\
\hline 2 & $67-73$ & 0 & 3 & -3 & 9 & 3 \\
\hline 3 & $74-80$ & 13 & 9 & 4 & 16 & 1,7 \\
\hline 4 & $81-87$ & 5 & 9 & -4 & 16 & 1,7 \\
\hline 5 & $88-94$ & 3 & 3 & 0 & 0 & 0 \\
\hline 6 & $95-101$ & 2 & 1 & 1 & 1 & 1 \\
\hline
\end{tabular}

Perhitungan ditemukan Chi Kuadrat hitung $=8,5$. Selanjutnya hasil perhitungan tersebut dibandingkan dengan harga Chi Kuadrat tabel dengan dk (derajat kebebasan) $6-1=5$. Berdasarkan tabel Chi Kuadrat dapat diketahui bahwa $\mathrm{dk}=5$ dan kesalahan yang ditetapkan $=5 \%$, maka harga Chi Kuadrat tabel 11,070. Karena harga Chi Kuadrat hitung $(8,5)$ lebih kecil dari harga Chi Kuadrat tabel $(11,070)$, maka distribusi data hasil belajar IPS peserta didik kelas eksperimen I dengan jumlah 25 siswa dinyatakan normal.

Uji Normalitas Eksperimen II

\begin{tabular}{|c|c|c|c|c|c|c|}
\hline No & Frekuensi & $\boldsymbol{f}_{\boldsymbol{o}}$ & $\boldsymbol{f}_{\boldsymbol{h}}$ & $\left(f_{0}-f_{h}\right)$ & $\left(f_{0}-f_{h}\right)^{2}$ & $\frac{\left(f_{0}-f_{h}\right)^{2}}{f_{h}}$ \\
\hline 1 & $45-50$ & 2 & 1 & 1 & 1 & 1 \\
\hline 2 & $51-56$ & 3 & 3 & 0 & 0 & 0 \\
\hline 3 & $57-62$ & 3 & 8 & -5 & 25 & 3,1 \\
\hline
\end{tabular}




\section{PERBANDINGAN HASIL BELAJAR IPS PESERTA DIDIK \\ MENGGUNAKAN METODE TANYA JAWAB DENGAN \\ METODE PEER TUTORING DI KELAS VII \\ MTS NURUL HUDA SUKARAJA}

\begin{tabular}{|c|c|c|c|c|c|c|}
4 & $63-68$ & 7 & 8 & -1 & 1 & 0,1 \\
\hline 5 & $69-74$ & 6 & 3 & 3 & 9 & 3 \\
\hline 6 & $75-80$ & 2 & 1 & 1 & 1 & 1 \\
\hline \multicolumn{2}{|c|}{ Jumlah } & $\mathbf{2 3}$ & $\mathbf{2 4}$ & $\mathbf{0}$ & $\mathbf{2 8}$ & $\mathbf{8 , 2}$ \\
\hline
\end{tabular}

Perhitungan ditemukan Chi Kuadrat hitung $=8,2$. Selanjutnya hasil perhitungan tersebut dibandingkan dengan harga Chi Kuadrat tabel dengan dk (derajat kebebasan) $6-1=5$. Berdasarkan tabel Chi Kuadrat dapat diketahui bahwa $\mathrm{dk}=5$ dan kesalahan yang ditetapkan $=5 \%$, maka harga Chi Kuadrat tabel 11,07. Karena harga Chi Kuadrat hitung $(8,2)$ lebih kecil dari harga Chi Kuadrat tabel $(11,07)$, maka distribusi data hasil belajar IPS kelas eksperimen II dengan jumlah 23 siswa dinyatakan normal.

\section{Uji Homogenitas}

$$
F=\frac{S_{1}^{2}}{S_{2}^{2}}=\frac{5,98}{5,42}=1,10
$$

Kriteria uji homogenitas tolak $\mathrm{H}_{\circ}$ jika $F_{\text {hit }} \geq F_{\text {tabel }}$ dengan $F_{\text {tabel }}=$ $F_{1 / 2 \alpha(V 1-v 2)}$. Dan terima $H_{0}$ untuk harga $F_{\text {hit }}<F_{\text {tabel. }}$. Serta besarnya $\alpha$ diambil 5\% $V_{1}=n_{1}-1$ dan $V_{2}=n_{2}-1$.(Sudjana, 2009: 239). Nilai $F_{\text {hitung }}$ kemudian dibandingkan dengan nilai $F_{\text {tabel }}$ pada derajat kebebasan untuk pembilang $V_{1}=n_{1}-1=25-1=24$ dan derajat kebebasan untuk penyebut $V_{2}=n_{2}-1=23-1=22$ dengan taraf signifikansi $5 \%$. $F_{\text {tabel }}=F_{0,05}$ $(24,22)=1,98$ dari perhitungan didapat $F_{\text {tabel }}=1,98$. Berdasarkan nilai $F$ yang diperoleh dapat dilihat bahwa $F_{\text {hit }}<F_{\text {tabel }}=1,10<1,98$, maka $H_{\circ}$ diterima. Dengan demikian dapat disimpulkan bahwa varian dalam penelitian ini adalah homogen.

\begin{tabular}{|c|c|c|}
\hline$F_{\text {tabel }}$ & $F_{\text {hitung }}$ & Keputusan \\
\hline 1,98 & 1,10 & Homogen \\
\hline
\end{tabular}




\section{UJI HIPOTESIS}

$$
Z=\frac{\bar{x}_{1}-\bar{x}_{2}}{\sqrt{\frac{1}{n_{1}}+\frac{1}{n_{2}}}}=\frac{80,64-64,20}{\sqrt{\frac{1}{25}+\frac{1}{23}}}=\frac{16,44}{\sqrt{\frac{23+25}{575}}}=\frac{16,44}{\sqrt{\frac{48}{575}}}=\frac{16,44}{\sqrt{0,083}}=\frac{16,44}{0,29}=56,7
$$

Dengan kriteria uji terima $H_{0}$ jika $-Z_{1 / 2(1-\alpha)}< \pm Z_{\text {hit }}<Z_{1 / 2(1-\alpha)} H_{0}$ diterima, dan jika $-Z_{1 / 2(1-\alpha)}> \pm Z_{\text {hit }}>Z_{1 / 2(1-\alpha)} H_{a}$ diterima. Dimana $Z_{1 / 2(1-}$ a) didapat dari daftar normal baku dengan peluang $1 / 2(1-\alpha)$ (Sudjana, 2009:239). Dengan taraf signifikan 5\%.

$$
\begin{array}{ll}
\mathrm{Z}_{\text {tabel }} & =\mathrm{Z}_{1 / 2(1-\alpha)} \\
\mathrm{Z}_{\text {tabel }} & =\mathrm{Z}_{1 / 2(1-0,05)} \\
\mathrm{Z}_{\text {tabel }} & =\mathrm{Z}_{1 / 2(0,95)} \\
\mathrm{Z}_{\text {tabel }} & =\mathrm{Z}_{0,475}
\end{array}
$$

Kriteria yang dipakai dari daftar normal baku untuk uji dua pihak dengan $\alpha=5 \%$ yang memberikan nilai $\mathrm{Z}_{0,475}=1,96$. Jadi kriteria pengujian yang dipakai adalah terima $\mathrm{H}_{0}$ jika $\mathrm{Z}_{\text {hit }}$ terletak antara $-1,96$ sampai dengan 1,96 .

\section{Pembahasan}

Setelah data masing-masing kelas diketahui dan dianalisis, langkah selanjutnya adalah mengetahui ada tidaknya perbedaan yang signifikan hasil belajar IPS peserta didik menggunakan metode tanya jawab dengan metode peer tutoring di kelas VII MTs Nurul Huda Sukaraja. Pengujian hipotesis dilakukan menggunakan uji $Z$ dan varian homogen serta data berdistribusi normal. Maka hipotesis dalam penelitian ini adalah :

Ho: Tidak terdapat perbedaan hasil belajar IPS siswa antara siswa yang menggunakan metode tanya jawab dengan siswa yang menggunakan metode peer tutoring di kelas VII MTs Nurul Huda Sukaraja. 


\section{PERBANDINGAN HASIL BELAJAR IPS PESERTA DIDIK \\ MENGGUNAKAN METODE TANYA JAWAB DENGAN \\ METODE PEER TUTORING DI KELAS VII \\ MTS NURUL HUDA SUKARAJA}

Ha : Terdapat perbedaan hasil belajar IPS siswa antara siswa yang menggunakan metode tanya jawab dengan siswa yang menggunakan metode peer tutoring di kelas VII MTs Nurul Huda Sukaraja.

Berdasarkan hasil penelitian yang dilakukan peneliti melalui tes objektif 20 soal berbentuk pilihan ganda dengan empat alternatif jawaban (a, b, c, d,). Nilai rata-rata hasil belajar IPS peserta didik menggunakan metode peer tutoring sebesar 80,64 sedangkan menggunakan metode tanya jawab 64,20. Hasil penelitian menunjukkan bahwa hasil belajar IPS peserta didik yang menggunakan metode pembelajaran peer tutoring lebih besar daripada hasil belajar IPS peserta didik yang menggunakan metode pembelajaran tanya jawab.

\section{SIMPULAN}

Berdasarkan analisis data dan hasil penelitian tentang perbandingan hasil belajar IPS peserta didik menggunakan metode tanya jawab dengan metode peer tutoring di kelas VII MTs Nurul Huda Sukaraja dapat disimpulkan bahwa:

1. Hasil belajar IPS peserta didik menggunakan metode peer tutoring terdapat 18 siswa yang mendapat nilai kategori tinggi, 6 siswa mendapat nilai kategori sedang dan 1 siswa mendapat nilai kategori rendah, dengan nilai rata - rata diperoleh 80,64.

2. Hasil belajar IPS peserta didik menggunakan metode tanya jawab terdapat 1 siswa yang mendapat nilai kategori tinggi, 7 siswa mendapat nilai kategori sedang dan 16 siswa mendapat nilai kategori rendah, dengan nilai rata - rata diperoleh 60,25.

3. Hasil pengujian hipotesis menunjukkan bahwa nilai $Z_{\text {hitung }}$ tidak terletak diantara $-Z_{\text {tabel }}$ dan $+Z_{\text {tabel }}$ yaitu diperoleh harga $Z_{\text {hitung }}=56,7$ dan $Z_{\text {tabel }}=1,96$ yang berarti bahwa $H_{0}$ ditolak dan $H_{a}$ diterima. Maka dapat dinyatakan bahwa terdapat perbedaan hasil belajar IPS peserta didik yang signifikan antara peserta didik yang menggunakan metode tanya jawab dengan peserta didik yang 
menggunakan metode peer tutoring di kelas VII MTs Nurul Huda Sukaraja.

Proses pembelajaran dengan menggunakan metode pembelajaran tanya jawab dengan peer tutoring harus lebih aktif mengungkapkan gagasan, bertanya serta aktif diskusi di dalam kelompok sehingga diperoleh pengetahuan yang bermakna dan dapat memperbaiki hasil belajar IPS peserta didik.Kepada peneliti berikutnya yang akan melakukan penelitian terhadap penerapan metode tanya jawab dengan metode peer tutoring membutuhkan pengelolaan kelas yang terencana dan terorganisir serta disiplin menggunakan waktu yang telah dialokasikan, sehingga pembelajarannya dapat terlaksana dengan baik dan maksimal

\section{UCAPAN TERIMAKASIH}

Penulis mengucapkan banyak terima kasih kepada semua pihak yang telah membantu dari proses awal penulisan hingga bisa terbitnya tulisan ini. Kepada teman dan sahabat yang selalu memberikan dorongan semangat untuk segera membuat tulisan. Kemudian, khsususnya bagi pengelola jurnal UTILITY yang telah bersedia menerbitkan tulisan ini.

\section{REFERENSI}

Abdullah, Sani. 2013. Inovasi Pembelajaran. Jakarta: Bumi Aksara.

Asfar, A. I. T., \& Nur, S. (2018). Model pembelajaran problem posing \& solving: meningkatkan kemampuan pemecahan masalah. CV Jejak (Jejak Publisher).

Balqis, P., Ibrahim, N. U., \& Ibrahim, S. (2014). Kompetensi pedagogik guru dalam meningkatkan motivasi belajar siswa pada SMPN 3 Ingin Jaya Kabupaten Aceh Besar. Jurnal Administrasi Pendidikan: Program Pascasarjana Unsyiah, 2(1).

Djamarah, Syaiful Bahri. 2010. Strategi Belajar Mengajar. Jakarta : Rineka Cipta.

Fatimatuzahroh, F., Nurteti, L., \& Koswara, S. (2019). Upaya Meningkatkan Hasil Belajar Peserta Didik Pada Mata Pelajaran Akidah Akhlak Melalui Metode Lectures Vary. Jurnal Penelitian Pendidikan Islam,[SL], 7(1), 35-50.

Nasution, M. K. (2018). Penggunaan metode pembelajaran dalam peningkatan hasil belajar siswa. Studia Didaktika, 11(01), 9-16. 


\section{PERBANDINGAN HASIL BELAJAR IPS PESERTA DIDIK MENGGUNAKAN METODE TANYA JAWAB DENGAN METODE PEER TUTORING DI KELAS VII MTS NURUL HUDA SUKARAJA}

Sudjana, Nana. 2009. Penilaian hasil proses belajar mengajar. Bandung : Remaja Rosdakarya.

Sugiyono, 2009. Metode Penelitian Pendidikan. Bandung : Alfabeta.

SOLATIYAH, S. (2016). EFEKTIFITAS PENERAPAN METODE TANYA JAWAB PADA PEMBELAJARAN PAI DI SMP 1 KALAENA KEC. KALAENA KAB. LUWU TIMUR (Doctoral dissertation, Institut Agama Islam Negeri Palopo).

Sutikno, M. Sobry. 2013. Belajar dan Pembelajaran. Lombok : Holistica. 